\author{
種光を用いた短波長自由電子レーザーの研究 \\ 今崎一夫*, 中尾 直也, 後藤 道夫**, 文 雅司 $*$, 大東 延久 $* * *$, 綱脇 恵章 $* * * *$, \\ 三間 图興 $* * * * *$, 中井貞雄, 山中千代衛* \\ 大阪大学工学部 ( $5565-0871$ 大阪府吹田市山田丘1-1) \\ * (財) レーザー技術総合研究所 (テ565-0871 大阪府吹田市山田丘2-6) \\ $* *$ 大阪大学 接合科学研究所 ( $5567-0047$ 大阪府茨木市美穗ヶ 丘 $11-1)$ \\ ***関西大学 ( $=564-8680$ 大阪府吹田市山手町3-5-35) \\ $* * * *$ 大阪産業大学 (干574-8530大阪府大東市中垣内3-1-1) \\ $* * * * *$ 大阪大学レーザー核融合研究センター (
}

\title{
Study of Short Wavelength Free Electron Laser with a Seed X-ray
}

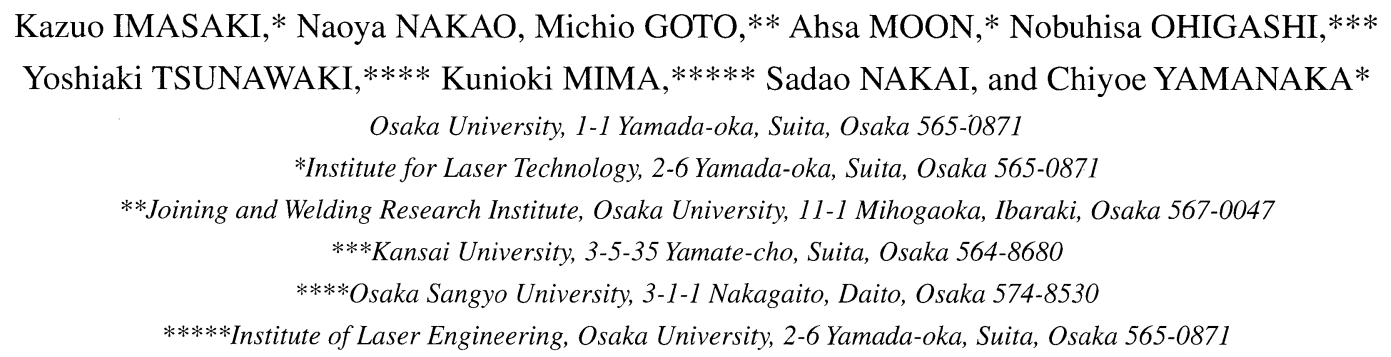

(Received November 11, 1999)

\begin{abstract}
On the development of short wavelength Free Electron Lasers, there is a issue of the extremely large system. It is caused by high energy accelerator and a long wiggler. In order to solve this, we propose a system utilizing a microwiggler and seeding X-rays. Microwiggler makes it possible to lase at the wavelength of vacuum ultraviolet to soft X-ray with low energy electron beam. With seeding X-ray, quick start-up and thus short wiggler length are expected. We examined the validity of seeding $\mathrm{X}$-ray using computer simulation. As a result, when seeding X-ray of $10 \mathrm{~kW}$ average power is supplied, it was shown that wiggler length for the radiation saturation was shortened by $60 \%$. We are going to use Laser-produced Plasma X-ray (LPX) for the seeding X-ray source. The technique of using an ellipsoid mirror to improve coupling efficiency of LPX to seeding X-ray is also discussed.
\end{abstract}

Key Words: SASE, Micro-wiggler, Seed X-ray, LPX

1.はじめに

X線のような短波長域の自由電子レーザー (Free Electron Laser, FEL) では, 光共振器を構成できる高反射率, 高耐力 ミラーが存在しないため, 共振器無しで発振を行う自己増 幅自然放射光 (Self Amplified Spontaneous Emission, SASE) 型のFELが検討されている1-3). しかし発振波長の短波長 化にともない, 高い電子ビームエネルギーが要求されるた め, 加速器および放射線遮蔽施設が大規模なものになると いう問題が生じてくる。ささらに, SASE FELの発振機構か ら, 非常に長尺のウィグラーが必要となり,このことも装 置開発の障害となっている。これらの問題を除くために 我々は電子ビームと同期した種光をマイクロウィグラー に入射し，それを増幅させることを提案する。

マイクロウィグラーを用いた場合, 数百 $\mathrm{MeV}$ の電子ビー
ムで真空紫外から軟X線領域の発振が可能となる。すなわ ち, 要求される波長域に対する電子ビームエネルギーを低 く抑えることが出来るため, 加速器の規模が比較的小さく 済む。また, 種光を用いて放射光の立ち上がりを早くする ことで, ウィグラー長の短縮化が見込め,これにより装置 開発が容易になる。現在, 著者らは, 自由電子レーザー研 究所 (Free Electron Laser Institute, FELI)において, $150 \mathrm{MeV}$ のライナックを用いたこのような方式の短波長FELの研究 を行っている.

2. SASEシミュレーション

種光を用いたSASE FELの増幅特性を解析するため, シ ミュレーションを行った. SASEでは放射光が電子ビーム に強く捕捉されるような強い相互作用を起こすため, 従来 
の様な共振器に依存した展開法では非常に高次のモード まで計算する必要がある。そのためこのシミュレーショ ンでは,電子ビーム依存展開 (Source Dependence Expansion, SDE)法を用いた. SDE法は, 放射光が電子ビームに強くト ラップされて波面が歪んだ場合でも低次の横モードの重 ね合わせで電磁波強度分布を記述できるので, 計算機シ ミュレーションとして非常に適している4). 今回, この SDE法によって記述した放射光の振幅の式と, その位相に 含まれる各粒子に対する運動方程式を連立させて解くこ とによって, 放射光と電子ビームとの空間発展を調べた。

Table 1はシミュレーションパラメータである。本報告 では, 電子ビームエネルギーが $150 \mathrm{MeV}, 330 \mathrm{MeV}$ 二つの 場合の結果を示す. $150 \mathrm{MeV}$ というのはFELIの電子ビーム エネルギーである．使用するウィグラーは周期長 $10 \mathrm{~mm} の$ ヘリカルマイクロウィグラー5)であり,このときの発振波 長は64.9nmと計算される。また, FELIの加速器は電子ビー ムのパルス持続時間を短縮することで約 $300 \mathrm{MeV}$ までエネ ルギーを上げることが出来る。電子ビームエネルギー $330 \mathrm{MeV}$ のとき波長は13.5nmとなるが, この波長は軟X線多 層膜反射ミラーの中で最も高い反射率が得られ, 産業応用 にも期待されている波長である6). また, $P_{0}$ は放射光の初 期值である.SDE法は増幅の計算をするので初期值の設定 が必要となる。この初期值には, 周波数拡がり, コヒーレ ンスのパラメータは含まれていない.また, $P_{0}=1 \mathrm{Wが}$ 種 X線を使用していない, 自然放射光ノイズからの発振の場 合に相当する.

シミュレーションの結果をFig.1, 2に示す．Fig.1はビー ムエネルギー $150 \mathrm{MeV}$, 発振波長64.9nmの場合である。（a） は放射光の成長の様子を, (b) は放射光の強度が1/eに減衰 する半径を表している。（a）に示されるように, 種X線を用 いていない場合 $\left(P_{0}=1 \mathrm{~W}\right)$, 放射光は $9 \mathrm{~m}$ の位置で飽和して いる。一方, $10 \mathrm{~kW}$ 種X線を打ち込んだ場合, 飽和までの

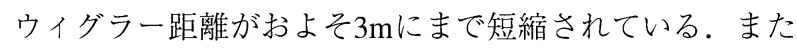
(a)，(b)より, 放射光の飽和と径の発散の位置が対応して いることが分かる. 放射光が飽和するときには電子ビー ムは大きく密度変調を受けており, 空間分布において極端 な粗密が生じる．そのため電子ビームのトラップ効果が 弱くなりガイディング条件が崩れ, 放射光は発散していく ものと考えられる. $6 \mathrm{~m}$ 付近に見られる放射光の一時的な 減衰は, 電子ビームのベータトロン振動によるものと考え

Table 1 The parameters for SASE simulation by SDE method.

\begin{tabular}{|c|c|}
\hline \multicolumn{2}{|l|}{ electron beam } \\
\hline$E_{\mathrm{b}}$ & $150,330 \mathrm{MeV}$ \\
\hline$I_{\mathrm{b}}$ & $200 \mathrm{~A}$ \\
\hline$r_{\mathrm{b}}$ & $100 \mu \mathrm{m}$ \\
\hline \multicolumn{2}{|l|}{ wiggler (helical) } \\
\hline$\lambda_{\mathrm{w}}$ & $10 \mathrm{~mm}$ \\
\hline$B_{\mathrm{w}}$ & $0.38 \mathrm{~T}$ \\
\hline$N_{\mathrm{w}}$ & 1000,3000 \\
\hline \multicolumn{2}{|l|}{ radiation } \\
\hline$\lambda_{\mathrm{s}}$ & $64.9,13.5 \mathrm{~nm}$ \\
\hline$r_{\mathrm{s}}$ & $120 \mu \mathrm{m}$ \\
\hline$P_{0}$ & $1-10 \mathrm{~kW}$ \\
\hline
\end{tabular}

第 28 巻第 6 号 種光を用いた短波長自由電子レーザーの研究
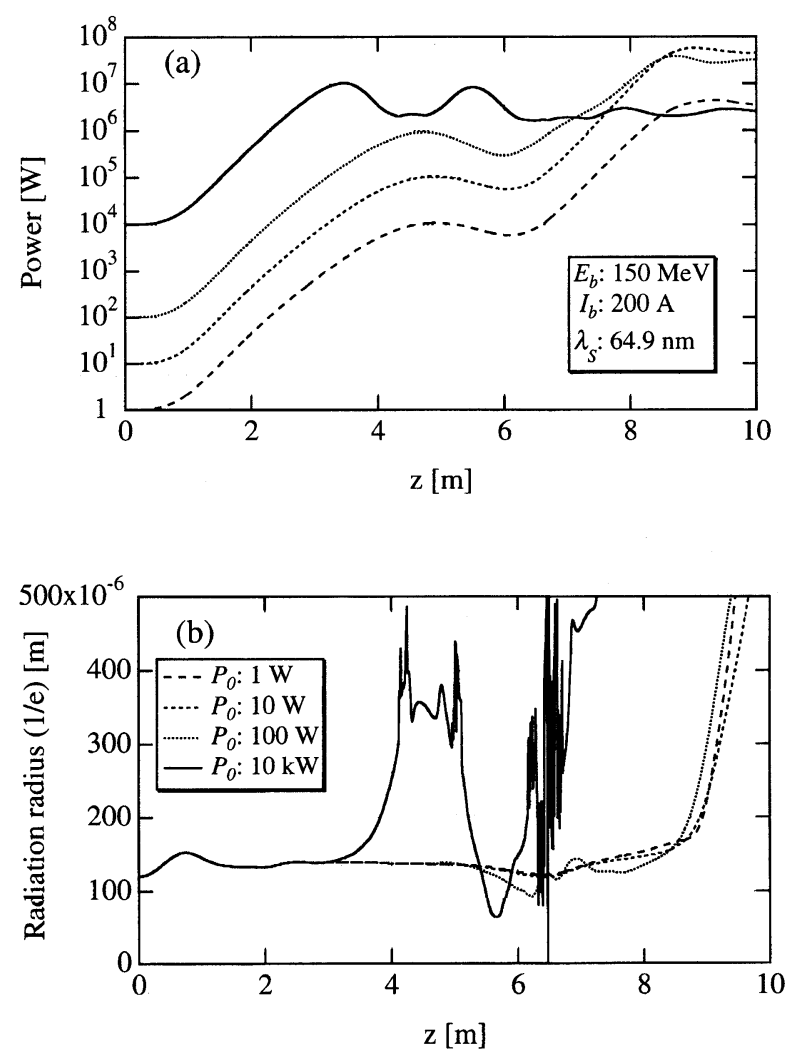

Fig.1 The result of the simulation by SDE-method. (a) The growth of SASE. (b) The 1/e radius of the radiation. The radiation wavelength is $64.9 \mathrm{~nm}$.

られる.SASE FELでは, 電子ビームに放射光がトラップ されながら相互作用が続いて行くが, 電子ビームのベータ トロン振動によってその効果が一時的に弱くなると考え られる. また, $P_{0}=10 \mathrm{~kW}$ 種X線を入射したときの放射光 径が激しく振動しているのは, 基本モードの振幅強度に対 して高次モードが支配的になるためである.

Fig.2はビームエネルギー330MeVの場合で, 発振波長は $13.5 \mathrm{~nm}$ である。種X線を用いなかった場合, 放射光はゆっ

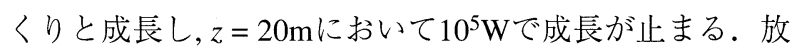
射光が $18 \mathrm{~m}$ 付近から発散しているため, これ以上の成長は 見込めない。一方, 種X線を用いた場合, $100 \mathrm{~W}, 10 \mathrm{~kW}$ とも に, $10^{7} \sim 10^{8} \mathrm{~W} て ゙$ 飽和に達している。 また, $10 \mathrm{~kW} 入$ 入射し た場合, 飽和距離は $8 \mathrm{~m} に ま て ゙$ 短縮されており, $100 \mathrm{~W}$ の種光 を入射したときに比べて $10 \mathrm{~m}$ 程度ウィグラー距離の短縮が 見込まれる。

これらの結果から,種X線を入射することによって飽和 までの距離が短縮されることがシミュレーションによっ て示された。これにより, ウィグラーの短縮化が期待でき る. また, 入射する種X線は, ベータトロン振動による影響 が出るよりも早く飽和に達するようなパワーを入射する ことが必要である.

\section{3. 種X線源}

種X線源に我々はレーザープラズマX線 (Laser Plasma Xray, LPX) を使用する．LPXは高強度レーザーをターゲッ トに集光照射したときに発生するプラズマから放射され 

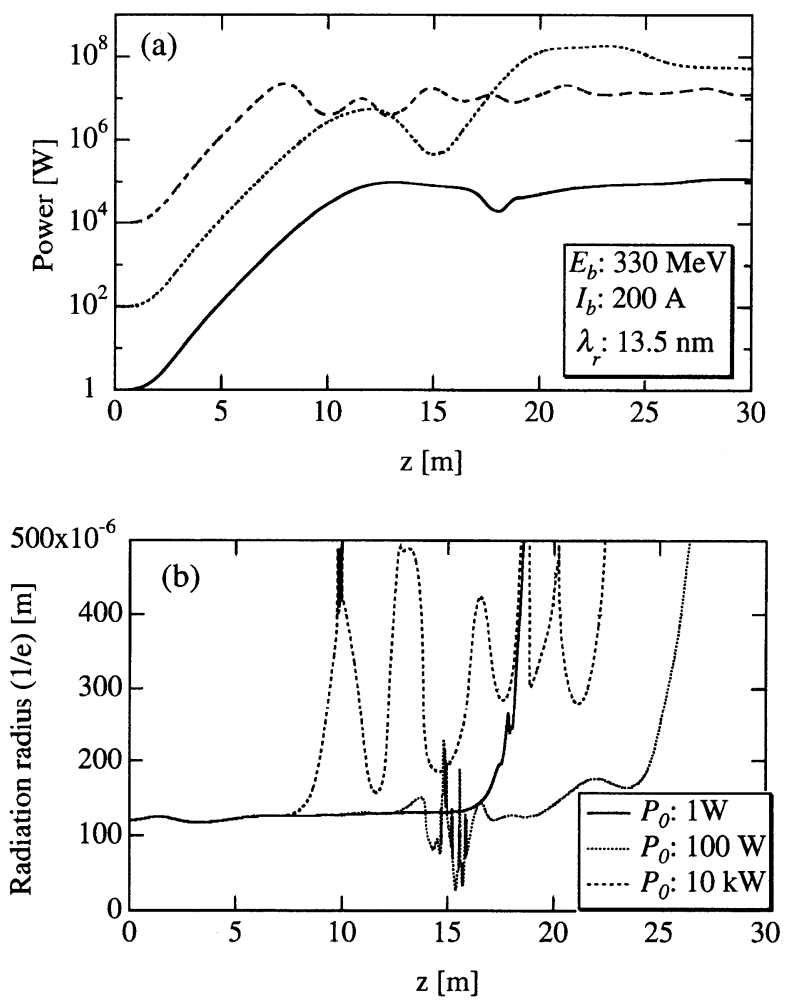

Fig.2 The result of the simulation by SDE-method. (a) The growth of SASE. (b) The 1/e radius of the radiation. The radiation wavelength is $13.5 \mathrm{~nm}$.

\section{るX線である7).}

ターゲット励起レーザーから種X線への変換効率の式を 導くためにFig.3に示すようなモデル図を仮定する。この 図の左側の部分はLPX発生部で右側はウィグラー, 電子 ビームである．励起用レーザーがターゲットに集光照射 されると, ターゲット表面にプラズマが形成され，そのプ ラズマからX線が放射される。このモデルでは, 放射され たX線のうち電子ビームとカップリングする立体角内に含 まれるX線だけが種X線として使用されることになる。

種X線のパワーP $P_{\mathrm{S}}$ は, LPXの総パワーP $P_{\mathrm{X}}$ と, LPXが電子 ビームとカップリングする効率 $\eta_{\mathrm{S}}$ とで,

$$
P_{\mathrm{S}}=\eta_{\mathrm{s}} P_{\mathrm{x}}
$$

と表される。ここで $P_{\mathrm{X}}$ は, 入射レーザーパワー $P_{\mathrm{L}}$ とその変 換効率 $\eta_{\mathrm{C}}$ から,

$$
P_{\mathrm{X}}=\eta_{\mathrm{C}} P_{\mathrm{L}}
$$

と表される。また, 発生したLPXのパワーのエンベロープ が球状である7)と仮定すると $\eta_{\mathrm{S}}$ は,

$$
\eta_{\mathrm{s}}=\frac{2 r_{\mathrm{b}}^{2}}{L^{2}}
$$

と表すことが出来る．よって, 入射レーザーから種X線へ の変換効率の式は,

$$
P_{\mathrm{S}}=\frac{2 \eta_{\mathrm{C}} r_{\mathrm{b}}^{2}}{L^{2}} P_{\mathrm{L}}
$$

と表される。

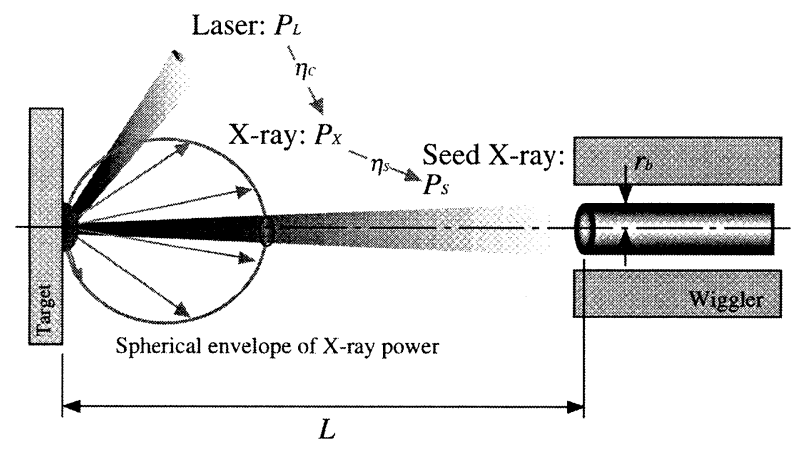

Fig.3 This is a model for derivation of conversion efficiency. $P_{\mathrm{L}}, P_{\mathrm{X}}$ and $P_{\mathrm{S}}$ are the power of incident laser, LPX and seed X-ray, respectively.

Fig.4に, 距離 $L$ を横軸にとった場合の種X線パワーを示 す。この図では, 入射レーザーパワー $P_{\mathrm{L}}$ を $1 \mathrm{GW}, \mathrm{LPX} へ の$ 変換効率 $\eta_{\mathrm{C}}$ を $1 \%$, 電子ビームの半径 $r_{\mathrm{b}}$ を $0.1 \mathrm{~mm}$ としてい る. 種X線のパワーは距離の逆2乗に比例するため, 大きな 種X線パワーを得るには距離 $L$ 小さくしなければならな w.

前章で示したシミュレーションの結果より,種X線の効 果を十分に発揮するには $10 \mathrm{~kW}$ 程度のパワーが必要であ る.しかし,Fig.3に示した方式で10kWの種X線を発生させ ることは非常に困難である。それはLPXから種X線への効 率が非常に悪い $\left(\eta_{\mathrm{S}}=10^{-7}\right)$ ことが主な原因であるが, 逆に このLPXを効率よく種X線として使用できれば，そのパ ワーは大きく改善されると言える. その方法として, Fig.5 に示すような回転楕円体や放物面のような反射光学系に よってLPXを集光することが考えられる. Fig.5に示した 楕円体ミラーの前半部分は, ターゲットからのデブリがミ ラー面上に付着しないように取り除かれている。プラズ マ発生点から角度 $\theta$ 内に放射されたX線が集光系に入る.

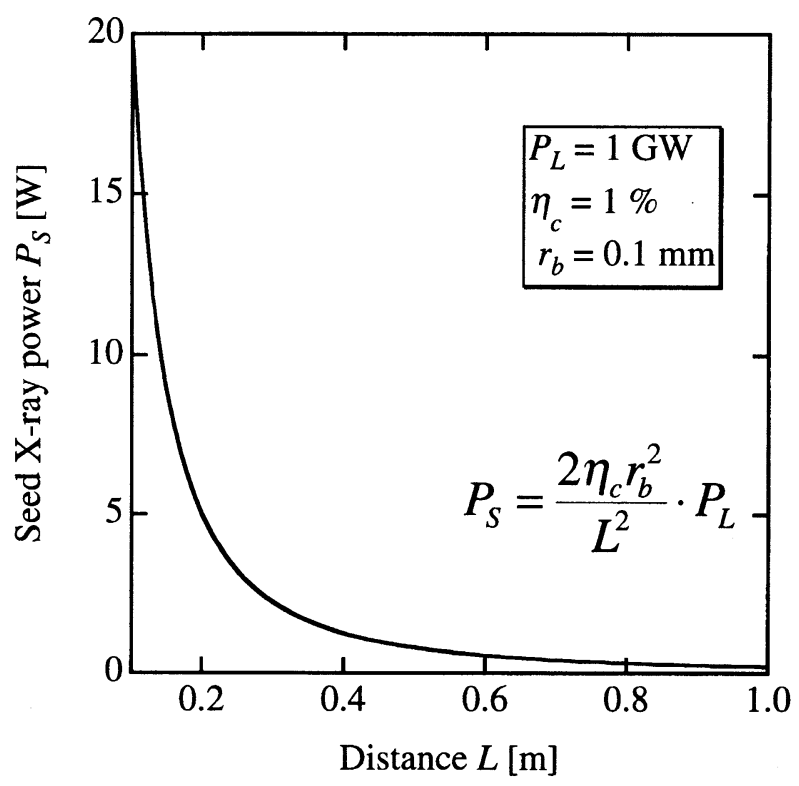

Fig.4 Seed X-ray power versus distance $L$. The distance is the space between target and wiggler. Incident laser power $P_{\mathrm{L}}$, conversion efficiency $\eta_{\mathrm{C}}$ and electron beam radius $r_{\mathrm{b}}$ are $1 \mathrm{GW}, 1 \%$ and $0.1 \mathrm{~mm}$, respectively. 


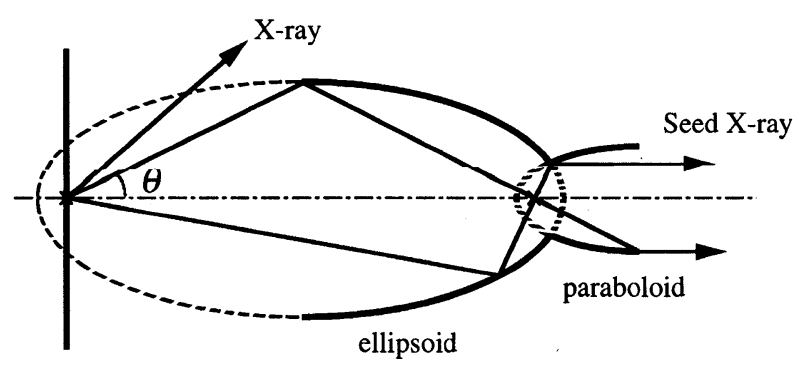

Fig.5 The examples for enhancement the seed X-ray. (a) Ellipsoid mirror. (b) Combination ellipsoid and paraboloid.

$\theta \approx 25^{\circ}$ のと,発生したX線の約 $10 \%$ ミミラーによって集光 される.このX線が全て種光になると見なすと, 効率はお よそ106倍改善されることになる。この条件でFig.4のパラ メータを用いると, 種光パワーは $1 \mathrm{MW}$ と計算される。

\section{4. まとめ}

装置規模の巨大さという, 短波長自由電子レーザー (FEL)の抱える問題を, ウィグラーにマイクロウィグラー を使用し,これに種光を入射し増幅させるという方法で解 決することを提案した。この種光の有効性を電子ビーム 依存展開法によるシミュレーションで確かめた．その結 果, $10 \mathrm{~kW}$ の種X線を入射した場合, 発振波長 $64.9 \mathrm{~nm}$ では飽 和に達するまでのウィグラー長は $9 \mathrm{~m}$ から $3 \mathrm{~m} に$ に また $13.5 \mathrm{~nm}$ の場合約 $20 \mathrm{~m}$ から $8 \mathrm{~m}$ に短縮できることが示され
た。これにより共振器が使用できない短波長FELにおける 長尺ウィグラーは小型化され, 容易に実現可能な範囲にな る。我々はこの種X線源としてレーザープラズマX線を考 えている。この技術はすでに確立されており, 導入は極め てスムーズに行われると考えられる．例えば, 原子番号50 のスズ $(\mathrm{Sn})$ をターゲットに使用した場合, $13.5 \mathrm{~nm}$ に対して $1 \%$ 程度の変換効率が得られている。ただし, LPXから種X 線への効率 $\left(10^{-7}\right)$ を増加させるため, 回転楕円体鏡や放物 面鏡などの反射光学系でLPXを集光する必要がある.

\section{参考文献}

1) Y. Wu, V. N. Litvinenko, and J. M. J. Madey: Nucl. Instr. and Meth. A341 (1994) 363.

2) W. Brefeld, B. Faatz, Y. M. Nikitina, J. Phlüger, P. Pierini, J. Roßbach, E. L. Saldin, E. A. Schneidmiller, and M. V. Yurkov: Nucl. Instr. and Meth. A375 (1996) 295.

3) R. Tatchyn, J. Arthur, M. Baltay, K. Bane, R. Boyce, M. Cornacchia, T. Cremer, A. Fisher, S. J. Hahn, M. Hernandez, G. Loew, E. Miller, W. R. Nelson, H. D. Nuhn, D. Palmer, J. Paterson, T. Raubenheimer, J. Weaver, H. Wiedemann, H. Winick, C. Pellegrini, G. Travish, E. T. Scharlemann, S. Caspi, W. Fawley, K. Halbach, K. J. Kim, R. Schlueter, M. Xie, D. Meyerhofer, R. Bonifacio, and L. De. Salvo: Nucl. Instr. and Meth. A375 (1996) 274.

4) M. Goto: Thesis of Osaka University (1999).

5) Y. Tsunawaki, Y. Okuda, N. Ohigashi, M. Kusaba, K. Imasaki, M. Fujita, K. Mima, and S. Nakai: Nucl. Instr. and Meth. (2000) (to be published).

6）山本 正樹：応用物理 62 (1993) 676.

7) I. C. E. Turcu and J. B. Dance: X-Rays from Laser Plasmas. Generation and Applications (Wiley 1999) p.131. 